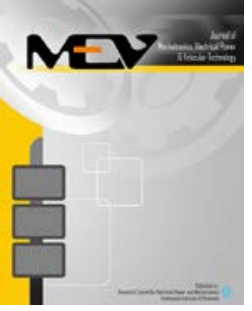

Journal of Mechatronics, Electrical Power, and Vehicular Technology

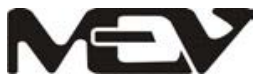

\title{
SIMPLE SUPERCAPACITOR CHARGING SCHEME OF AN ELECTRIC VEHICLE ON SMALL-SCALE HARDWARE SIMULATOR: A PRototyPE DEVELOPMENT FOR EDUCATION PURPOSE
}

\author{
Adnan Rafi Al Tahtawi ${ }^{a}{ }^{a}$, Arief Syaichu Rohman ${ }^{b}$ \\ ${ }^{a}$ Department of Computer Engineering, Politeknik Sukabumi \\ Jl. Babakan Sirna No. 25, Sukabumi, Indonesia \\ ${ }^{\mathrm{b}}$ Laboratory for Control and Computer Systems, Institut Teknologi Bandung \\ Jl. Ganesha No. 10, Bandung, Indonesia
}

Received 14 September 2016; received in revised form 20 October 2016; accepted 23 October 2016 Published online 23 December 2016

\begin{abstract}
Supercapacitor is one of electrical energy sources that have faster charging-discharging times when compared to other power sources, such as battery and fuel cell. Therefore, it is often used as an additional power source in an electric vehicle. In this paper, a prototype of small-scale electric vehicle simulator (EVS) is built and a simple charging scheme of supercapacitor is used for education purpose. EVS is an electric vehicle prototype which can show the vehicle's powertrain on small-scale configuration. Main components of this device are two direct current motors (DCMs) with a linked axis of rotation. Therefore one of them will be able to act as a generator. The supercapacitor charging scheme is employed by controlling the relays. The hardware experimental result shows that the averages of charging current are proportional to the maximum slope angle of the road profiles. This scheme is simple due to the EVS utility and it is useful for education purpose.
\end{abstract}

Keywords: supercapacitor; charging; electric vehicle simulator (EVS); direct current motor (DCM).

\section{INTRODUCTION}

Nowadays, electric vehicle researches are still being conducted. One of the research problems is the use of the battery as an electrical energy source for this vehicle. The limitation of battery lifetime impacts the vehicle's traveling time. Therefore, the specific technique is required to extend its lifetime. One of the solutions to overcome this problem is utilizing the additional power sources. Supercapacitor is one of electrical energy sources that have a higher capacity of storing energy compared to a normal capacitor. This component also has faster chargingdischarging times when compared with other power sources. Supercapacitor was worked as an electrical source with the highest frequency, while the battery was power source with a frequency between the fuel cell and supercapacitor [1]. It means that the chargingdischarging times of supercapacitor are faster

* Corresponding Author.Tel: +6281809214709

E-mail: adnanrafi@polteksmi.ac.id than the others. Due to this advantage, supercapacitors are often used as an additional power source in an electric vehicle. On the other hand, the electric motor as the main drive in electric vehicles may be utilized as a source of electrical energy through the regenerative braking. This process is used for electric energy charging. However, the problem is that the charging of the batteries takes a long time while the regenerative braking may take place in a relatively short time. By having a faster charging-discharging time, it is capable of storing electric energy faster, and the received electric energy during regenerative braking can be maximized. Therefore, it was needed the specified strategy and technique to overcome this problem.

Several solutions have been investigated and discussed. A battery-supercapacitor energy management and optimization for electric vehicles have been discussed by Choi et al. [2] and S. Pay et al. [3]. Modeling, evaluation, and simulation of the applications of supercapacitors 
in power electronics have been investigated by Zhang et al. [4] and Cultura et al. [5]. The charging and discharging methods of this device have also been presented Chan et al. [6] and Ban et al. [7]. As an addition, the various balancing circuits were used to overcome the imbalance of supercapacitor's voltage in series, as discussed by Diab et al. [8] and Qu et al. [9].

In this paper, we will design the supercapacitor charging scheme and implement it on an electric vehicle simulator (EVS). A laboratory at University of Pennsylvania, mLAB, has developed an EVS in small scale by using a direct current motor (DCM) as the main component, known as Protodrive. Protodrive board was modular and rapid prototyping friendly, and the power flow indicator lights make it intuitive to understand how energy was transferred through the system (electric vehicle) [10]. In its demonstration, a velocity profile, altitude data, vehicle parameters and weather data were used as inputs to generate a scaled torque and speed profile which will be run on the Protodrive hardware [11]. S. Diaz [12], has designed various road profiles to show the voltages required by the DCMs on the Protodrive. Battery-supercapacitor energy management on Protodrive has been investigated by W. Price [13] with the result was consumption of battery power could be reduced by $23.23 \%$. Lastly, the control algorithm has been described to run Protodrive by Mulay et al. [14]. This paper presents a simple charging scheme of a supercapacitor in an electric vehicle. The simple supercapacitor charging scheme is designed and implemented on an EVS which refers to Protodrive. The road profiles are designed at three types of road profile scenarios, i.e. one hill, two hills and trapezoidal. In this paper, the simple supercapacitor charging schemes will also be elaborated more detail and comprehensive.

\section{Electric Vehicle Simulator}

The EVS is built to simulate the power train in electric vehicles on a small scale configuration. By using this device, electric vehicle's power train will be more easily observed with obtained various scenarios. The preliminary simulator has been built by mLab University of Pennsylvania known as Protodrive. In this paper, an EVS is built referring to Protodrive by using component and configuration which are slightly different, as presented by Al Tahtawi et al. [15]. The main components of the simulator are two DCMs which are directly connected each other by their axis of rotation. The torque generated by DCM1 is assumed as the torque needed by vehicle's wheels, while the other is assumed as the torques due to forces from surroundings which interacted with the vehicle.

The EVS configuration consists of five main components, i.e. two units of DCM, battery, supercapacitor module, and microcontroller. Current sensors, speed sensor, voltage sensors, DC/DC converters, L298N H-bridge modules, power supply, and SPDT relays are also used as supporting components. Unlike Protodrive, this simulator uses separated DC/DC converters and H-bridge with SPDT relays, while Protodrive uses DCM controller with regenerative braking compatibility and equipped by DC/DC converter. Besides that, microcontroller that used in this EVS is ATMega 2560 on Arduino Mega 2560 board (Protodrive uses mBed microcontroller board by ARM). Lastly, this EVS using DC power supply for DCM2 (not using the battery as Protodrive). Block diagram of EVS which was modified from Protodrive is depicted in Figure 1.

To simulate an actual electric vehicle, a particular algorithm is needed. In this paper, the designed algorithm is aimed to calculate the voltages needed for the two mechanically connected DCMs as presented by A. Botelho and W. Price [10], S. Diaz [12], and W. Price [13]. The algorithm for each DCM is called first and second algorithms respectively. Where as in research doing by A. Mulay et al. [14], the algorithms were aimed at obtaining the voltage of DCM1 and the current of DCM2 for closed loop torque controls. The block diagram of the first algorithm that used in this paper is shown in Figure 2. The first algorithm needs two inputs, i.e. speed profile and road profile, and it has output voltages for two DCMs. The chosen speed profile is a constant speed of $10 \mathrm{~m} / \mathrm{s}$ or $36 \mathrm{~km} / \mathrm{h}$, while the chosen road profiles consisted of three types, i.e. one hill, two hills, and trapezoidal profiles. The data collected from the aforementioned three road profiles is a slope angle of the road for every pre-determined distance. As a comparison, the second algorithm has two references, which are speed and torque. This algorithm is also using control system, such as PID controller, to reach the given references. Thus, the first algorithm used in this study for simplicity due to education purpose.

The first step for running this EVS is designing the speed and road profiles. Designs of both profiles are done by using MATLAB/M-file. Speed profile is designed using the constant function. Hills road profiles are designed using sinusoidal functions, while trapezoidal road profile is designed using partial linear equation. Slope angle of road profile obtained by utilizing 


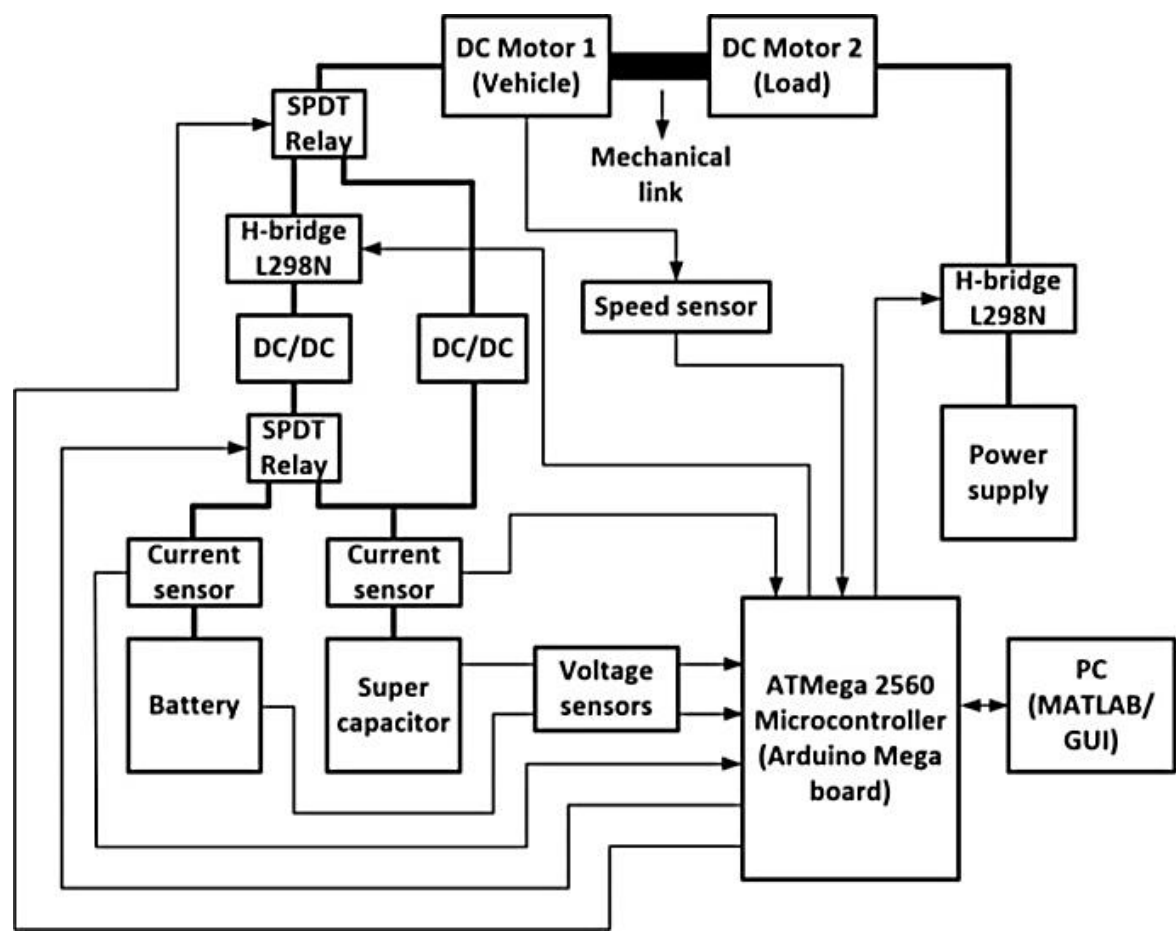

Figure 1. Block diagram of EVS

the gradient method. Road condition is also limited to uphill and downhill with no turn conditions.

Referring to Protodrive, the voltages needed by the two DCMs, as mentioned in the first algorithm, may be calculated as the following derivation.

$$
F_{t}=F_{a}+F_{g}+F_{d}+F_{r}
$$

where $F_{t}, F_{a}, F_{g}, F_{d}$, and $F_{r}$ respectively are forces of total traction at the wheels, acceleration, gravity, aerodynamic drag and rolling resistance of the tires. Based on Ehsani et al. [16], those forces are derived from these following equations:

$$
\begin{aligned}
& F_{a}=m a \\
& F_{g}=m_{v} g \sin (\theta) \\
& F_{d}=\frac{1}{2} \operatorname{sign}\left(v+v_{w}{ }^{2}\right) \rho_{a} A_{f} C_{d}\left(v+v_{w}{ }^{2}\right) \\
& F_{r}=\operatorname{sign}(v) C_{r} m_{v} g \cos (\theta)
\end{aligned}
$$

where $m$ and $m_{v}$ are total mass acting on the wheels and mass of vehicle, $a$ and $g$ are acceleration and gravity, $\theta$ is road's slope angle, $v$ and $v_{w}$ are vehicle and wind velocities, $\rho_{a}$ is air density of dry air at $20^{\circ} \mathrm{C}, A_{f}$ is vehicle's frontal area, $C_{d}$ and $C_{r}$ are coefficients of aerodynamic drag and tire rolling resistance. Total mass acting on the wheel is obtained from addition between mass of wheels and mass of vehicle. Coefficient of rolling resistance is defined as follows [16]:

$$
C_{r}=0.01\left(1+\frac{3.6}{100} v\right)
$$

The torque acted on the vehicle is then calculated in accordance with this following equation:

$$
T=F_{t} r T_{\text {scalling }}
$$

where $T, T_{\text {scalling }}$, and $r$ are torque, its scale and radius of the wheels. The torque is scaled and then used to calculate the two voltages needed by the two DCMs. It must be conducted due to

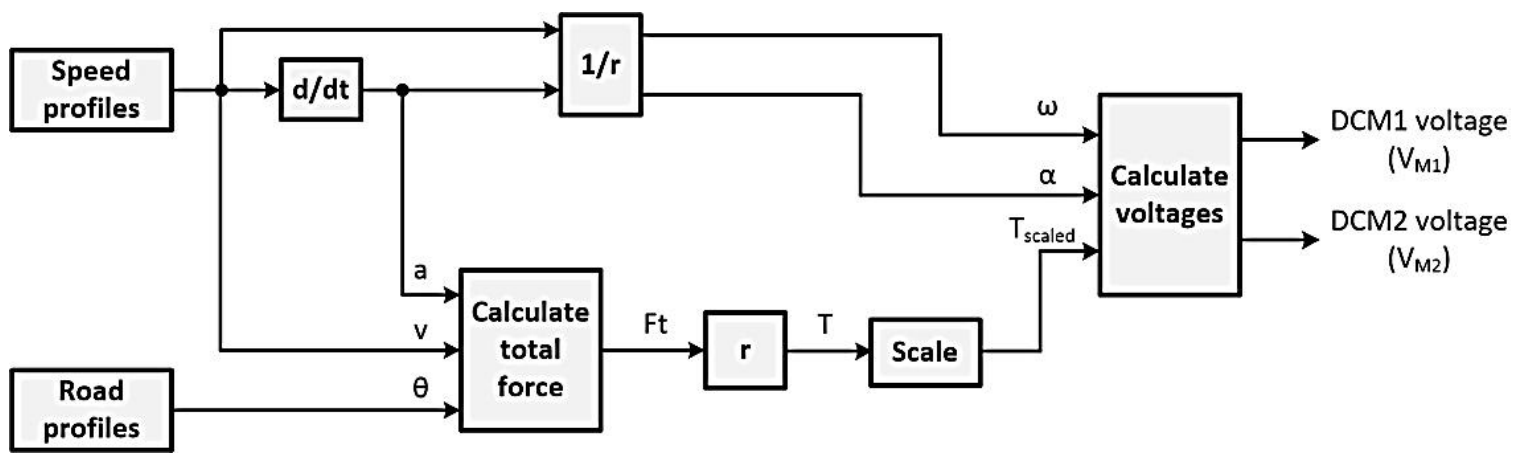

Figure 2. First algorithm of EVS 


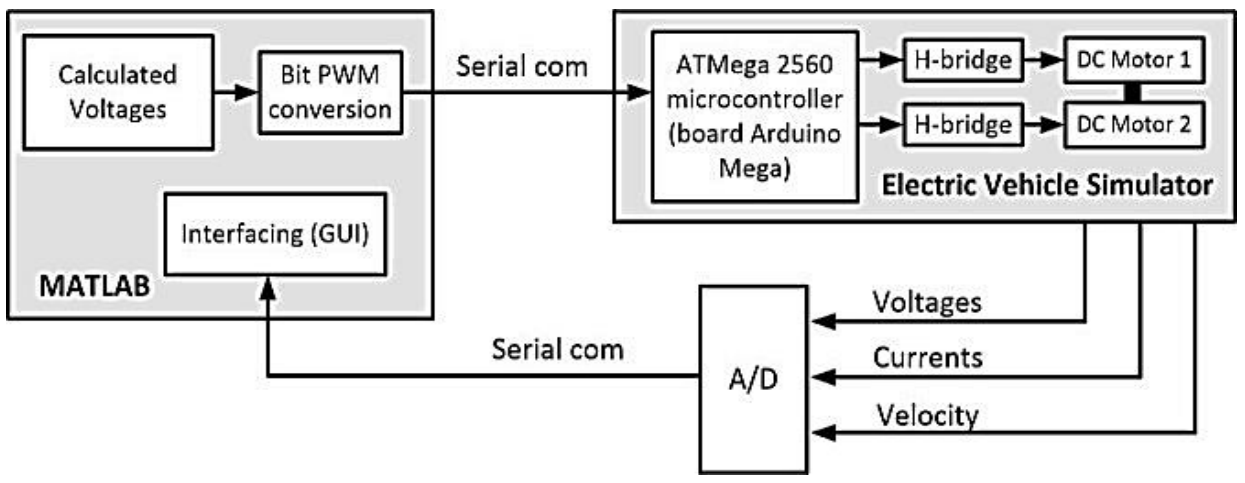

Figure 3. Communications between EVS and PC

small-scale configuration of the EVS. The two voltages are obtained by referring to the DCM electric equation as follows:

$$
\begin{aligned}
& V_{M 1}=R i_{M 1}+L \frac{d i_{M 1}}{d t}+V_{b e m f} \\
& V_{M 2}=R i_{M 2}+L \frac{d i_{M 2}}{d t}+V_{b e m f}
\end{aligned}
$$

where $V_{M 1}$ and $V_{M 2}$ are both of DCM voltages, $R$ is resistance, $i_{M 1}$ and $i_{M 2}$ are currents of DCMs, $L$ is inductance, $V_{\text {bemf }}$ is back electromotive force voltage. Since the two motors are connected then $V_{\text {bemf }}$ produced will be equal and fulfilled:

$$
V_{\text {bemf }}=k \omega
$$

where $k$ and $\omega$ are motor's constant and DCM's angular velocity. Whereas, the rotational motion equation of the two mechanically connected DCMs (no friction assumption) is the following:

$$
T_{M 1}+T_{M 2}=J \alpha
$$

where $T_{M 1}$ and $T_{M 2}$ are both of DCM torques, $J$ is moment of inertia, $\alpha$ is angular acceleration. By using the connection between torque and current:

$$
i=\frac{T}{k}
$$

then from equations (8) and (9), under the assumption that the inductance value of each DCM was small, the followings are obtained:

$$
\begin{aligned}
& V_{M 1}=R \frac{T_{M 1}}{k}+k \omega \\
& V_{M 2}=R \frac{J \alpha-T_{M 1}}{k}+k \omega
\end{aligned}
$$

These voltages are calculated in MATLAB/Simulink and then sent to the DCMs through microcontroller and H-bridge module in the form of PWM signals. In the same time, the battery-supercapacitor currents, batterysupercapacitors voltages, and DCM's velocity are monitored through MATLAB/GUI (Figure 3). Generally, the steps for running this EVS are: (1) upload the EVS code to the microcontroller; (2) run speed and road profiles codes in MATLAB/M-file; (3) run calculate voltages code in MATLAB/Simulink; and (4) run MATLAB/GUI code for monitoring. The sampling time for communication between EVS and PC is determined by one second.

After designing the EVS, the next step is hardware implementation. Hardware implementation of EVS is conducted referring to block diagram in Figure 1. The designed EVS is shown in Figure 4.

\section{III.SUPERCAPACITOR CHARGING SCHEME}

\section{A. Supercapacitor Module}

The supercapacitor used in this study is built in a module form. The module consisted of four cells of $100 \mathrm{~F} / 2.7 \mathrm{~V}$ supercapacitor and formed in series, so the module has $25 \mathrm{~F} / 10.8 \mathrm{~V}$. Based on Nesscap [17], specifications of the supercapacitor are presented in Table 1.

To overcome the imbalance of voltage of the supercapacitor in series, the module is also equipped with a balancing circuit. A passive balancing circuit is used due to its simplicity in terms of design and implementation.

Table 1.

Supercapacitor specifications [17]

\begin{tabular}{ll}
\hline Parameters & Values \\
\hline $\begin{array}{l}\text { Maximum internal resistance (ESR) } \\
\text { DC 11 A }\end{array}$ & $13 \mathrm{~m} \Omega$ \\
\hline Rated current $\left(25^{\circ} \mathrm{C}\right)$ & $21.4 \mathrm{~A}$ \\
\hline Maximum current $\left(25^{\circ} \mathrm{C}\right)$ & $>58.7 \mathrm{~A}$ \\
\hline Maximum leakage current $\left(12 \mathrm{~h}, 25^{\circ} \mathrm{C}\right)$ & $1.7 \mathrm{~mA}$ \\
\hline Maximum stored energy (at $2.7 \mathrm{~V})$ & $364.5 \mathrm{Joule}$ \\
& $(0.1013 \mathrm{Wh})$ \\
\hline Specified energy & $4.5 \mathrm{Wh} / \mathrm{kg}$ \\
\hline Specified power (at matched load) & $6.23 \mathrm{~kW} / \mathrm{kg}$ \\
\hline Volume & $17.1 \mathrm{ml}$ \\
\hline Weight & $22.5 \mathrm{~g}$ \\
\hline Cycle life $\left(25^{\circ} \mathrm{C}\right)$ & $500,000 \mathrm{cycles}$ \\
\hline
\end{tabular}




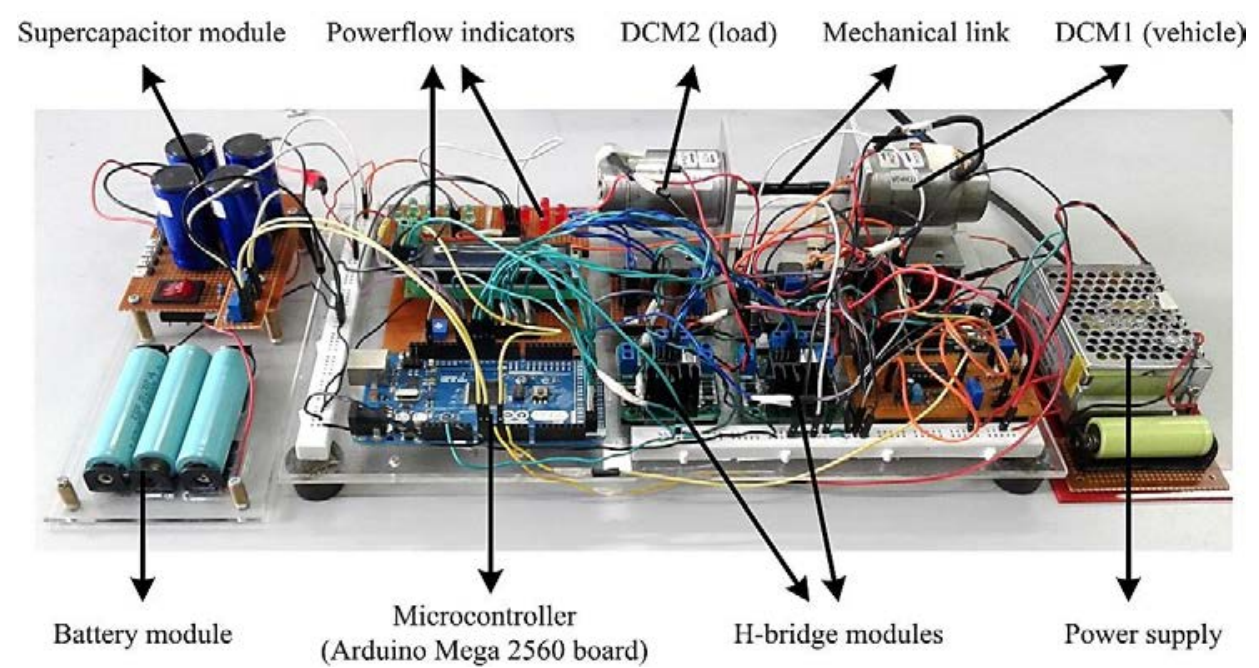

Figure 4. Hardware implementation of EVS

The balancer is formed by installing a parallel resistor in each supercapacitor cell as shown in Figure 5. In this way, the current resulted during the imbalance will flow to the resistor. The resistor value is $150 \Omega$ that obtained from following equation based on [8].

$$
R=\frac{V_{\text {sc maks }}}{10 . I_{\text {leakage }}}
$$

where $R$ was the resistance of balancing resistor, $V_{s c}$ maks was maximum supercapacitor cell's voltage, and $I_{\text {leakage }}$ was current leakage for each supercapacitor cell.

\section{B. Proposed Charging Schemes}

The design of supercapacitor charging scheme is conducted by controlling the relays. The relays which used in this study are a single pole double throws (SPDT) relays. The input of this component is obtained from microcontroller's digital signal. When the input signal logic is $\mathrm{HIGH}$, the switch in Common (C) pin will move from Normally Close (NC) pin to Normally Open (NO) pin.

The proposed supercapacitor charging scheme is shown in Figure 6. The red arrow shows the discharging current, while green arrow shows the charging current. Relay1 (R1) controls the switch between battery and supercapacitor, while the other (R2) controls between charging and discharging conditions. Specifications of DCMs that used are: R1 = 23 Ohm; R2 = 21.51 Ohm; L1

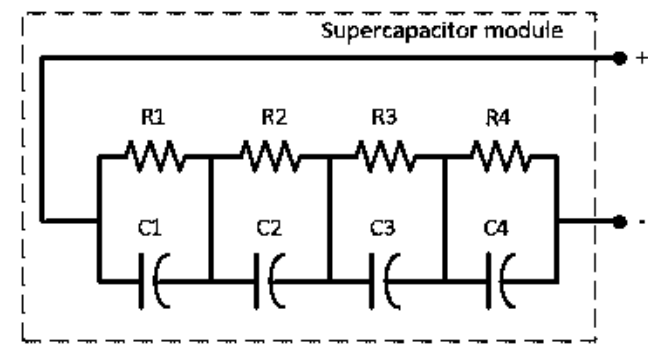

Figure 5. Supercapacitor balancing circuit
$=\mathrm{L} 2=0.1 \mathrm{H} ; \mathrm{K} 1=\mathrm{K} 2=0.055 ; \mathrm{b} 1=\mathrm{b} 2=0.01$ N.m.s; J1 = 0.0143 Kg.m ${ }^{2} ; \mathrm{J} 2=0.0146 \mathrm{Kg} . \mathrm{m}^{2} . \mathrm{R}$ is DCM resistance, $\mathrm{L}$ is DCM inductance, $\mathrm{K}$ is motor constant, b is friction constant, and $\mathrm{J}$ is moment of inertia. 1 and two are mentioned for DCM1 and DCM2. These parameters obtained from identification by direct experiment based on DCM's parameter measurement rules. To regulate and step up the generator voltage, a DC/DC2 boost converter is placed between the generator and supercapacitor. The DC/DC2 is used to regulate generator's voltage by $10.8 \mathrm{~V}$ during charging condition in accordance with supercapacitor's maximum voltage, while the other (DC/DC1) is used to regulate battery and supercapacitor voltages by $12 \mathrm{~V}$ while discharging condition occurs. DC/DC boost converter that used in this scheme has been integrated into LM2577-ADJ module. This converter works by switching the transistor using PWM signal. The connection between output and input voltages of this converter fulfilled this equation:

$$
V_{\text {out }}=\frac{V_{\text {in }}}{1-P W M \text { duty cycle }(\%)}
$$

As an approach, the charging scheme occurs during the regenerative braking process of the electric vehicle. During the braking, the electric motor in the vehicle will act as a generator. Energy produced by this generator will then be used as the electric energy source to charge the supercapacitor.

This scheme occurs when the vehicle is at the downhill profile. It is implemented by applying no voltage to DCM1. The DCM1's voltage which is calculated in MATLAB/Simulink based on speed and road profiles is set to be zero, so the motors will be running by DCM2's voltage. This strategy is done by detecting both of the motor voltages with this equation: 


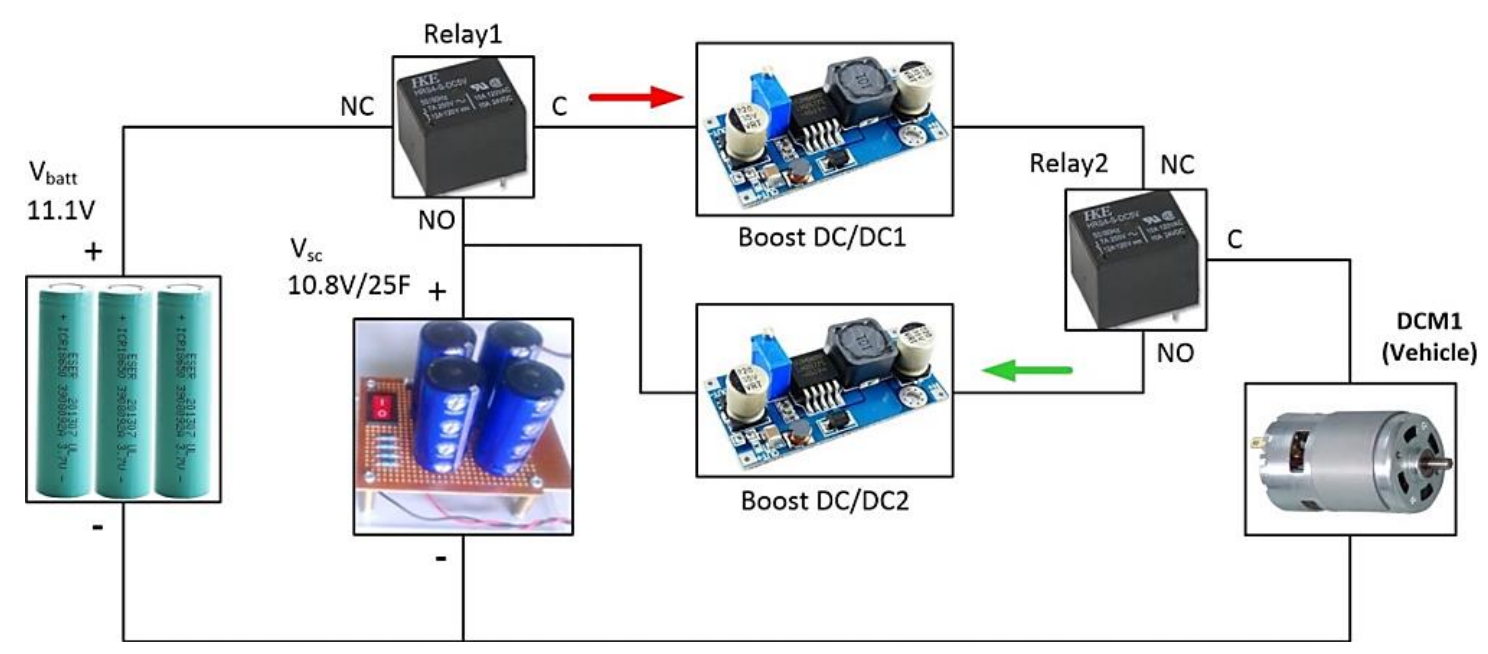

Figure 6. Proposed charging scheme

$$
V_{M 1}=\left\{\begin{aligned}
V_{M 1}, & V_{M 1} \geq V_{M 2} \\
0, & V_{M 1}<V_{M 2}
\end{aligned}\right.
$$

$V_{M 1}$ is DCM1 (vehicle) voltage and $V_{M 2}$ is DCM2 (load) voltage. First condition $\left(V_{M 1} \geq V_{M 2}\right)$ is assumed when the vehicle at the uphill or flat road profile, while the second condition $\left(V_{M 1}<V_{M 2}\right)$ is assumed when the vehicle at the downhill road profile. This algorithm is used because of the linearity connection between voltage and torque on electric vehicle. The supercapacitor charging occurs when the second condition is fulfilled. Thus, the voltage produced by DCM1 (vehicle/generator) due to DCM2's voltage is used as an electric energy source to charge the supercapacitor. The discharging condition is done when the supercapacitor voltage is defined ready. Supercapacitor is defined ready if its voltage is larger than $5 \mathrm{~V}$. This condition is conducted by sensoring the supercapacitor's voltage. To overcome the relay's chattering due to inaccuracies of sensor values when the supercapacitor voltage around $\pm 5 \mathrm{~V}$, the hysteresis control is used in the discharging condition. The values of lower and upper limits are $4 \mathrm{~V}$ and $6 \mathrm{~V}$. Variables which used are supercapacitor voltage $\left(V_{S C}\right)$ and its change $\left(\mathrm{d} V_{s c} / \mathrm{dt}\right)$. Supercapacitor is defined ready if (1) $V_{S C}>4$ and $\mathrm{d} V_{S C} / \mathrm{dt}<0$, or (2) $V_{S C}>6$ and $\mathrm{d} V_{s c} / \mathrm{dt}>0$. Figure 7 shows the flowchart of supercapacitor charging/discharging scheme. This flowchart is part of the overall flowchart of the hardware simulator.

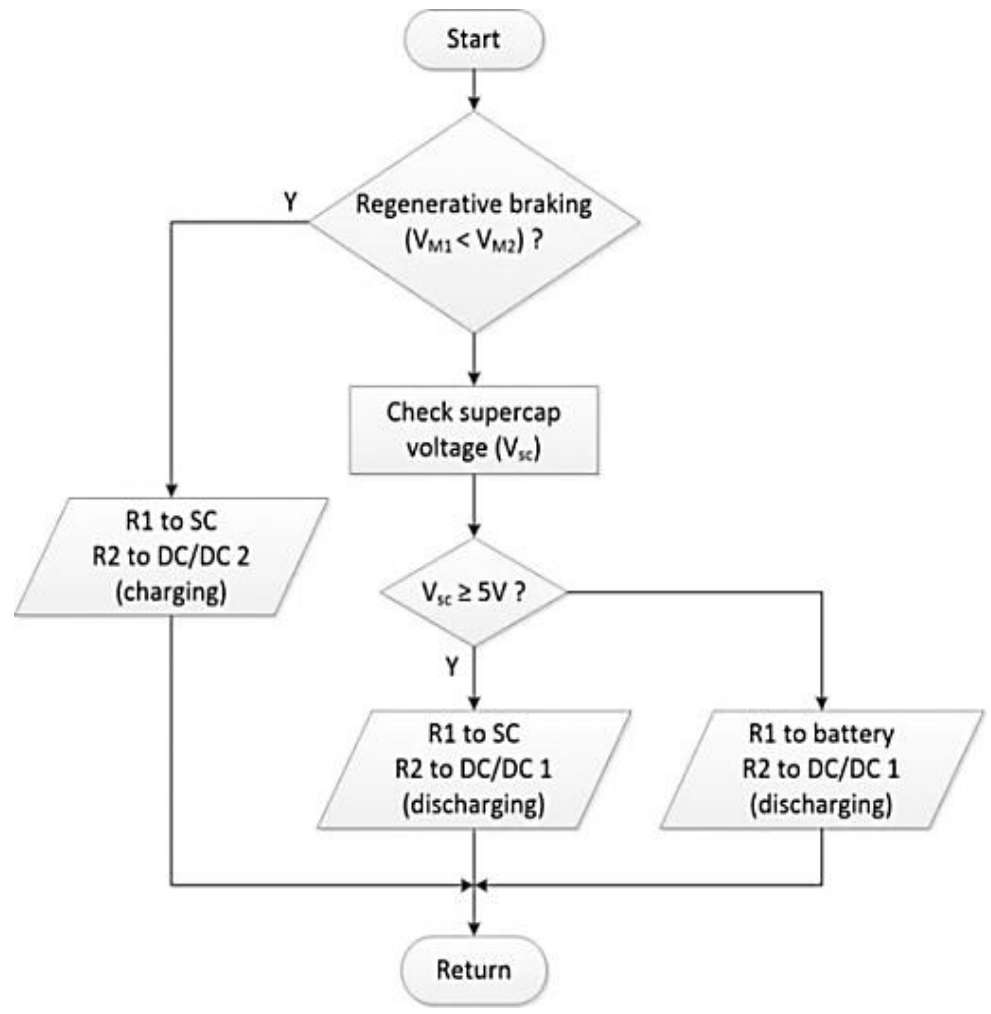

Figure 7. Supercapacitor charging/discharging flow chart 


\section{EXPERIMENTAL RESULT}

To have an appropriate simulation, the actual parameters of an electric vehicle are determined. This parameter is then used to calculate the voltages applied to DCMs. The parameters of the vehicle are listed in Table 2.

In this simulation, the torque is scaled by $1: 10^{5}$. Air density of dry air at $20^{\circ} \mathrm{C}$ is determined by $1 \mathrm{~kg} / \mathrm{m}^{3}$ and wind velocity is ignored for simplicity. This test is done with vehicle's speed constant $36 \mathrm{~km} / \mathrm{h}$ or $10 \mathrm{~m} / \mathrm{s}$ or $166.7 \mathrm{rad} / \mathrm{s}$ with $0.3 \mathrm{~m}$ radius of the wheel. The road profile scenarios are one hill, two hills and trapezoidal with maximum slope angle respectively are $8.52^{\circ},-16.66^{\circ}$, and $-11.3^{\circ}$.

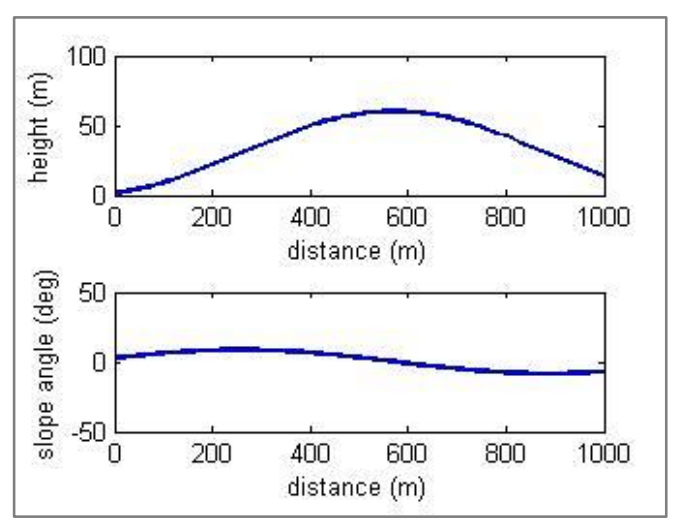

(a)

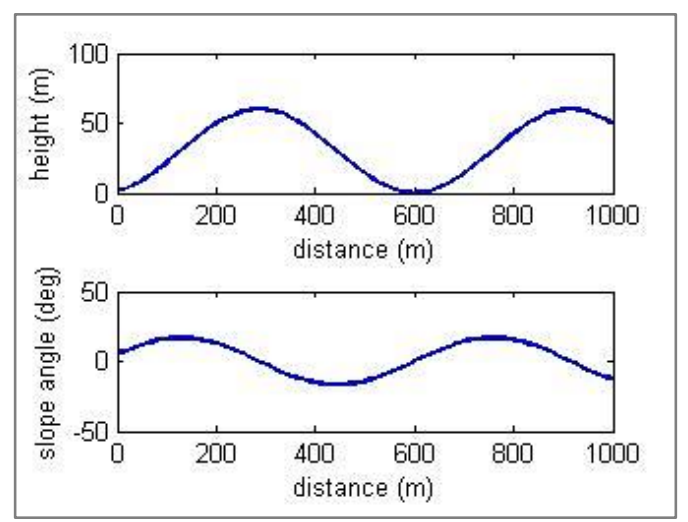

(b)

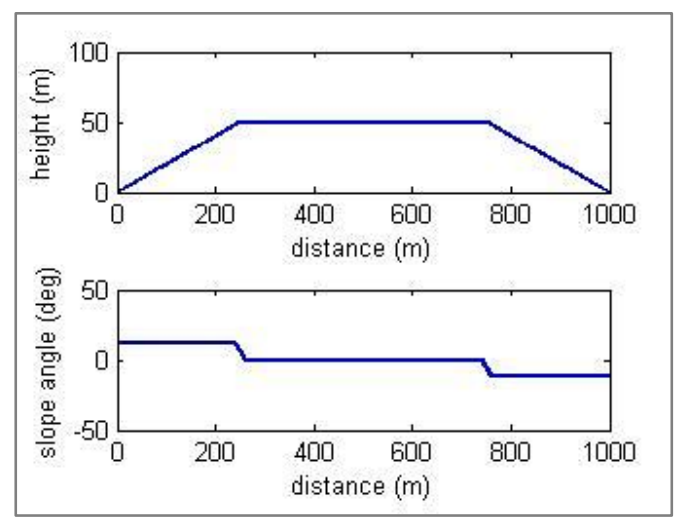

(c)

Figure 8. Road profiles and its slope angles: (a) one hill; (b) two hills; (c) trapezoidal
Designs of road profiles are shown in Figure 8 followed by its DCM voltages in Figure 9. As shown in Figure 9, the DCM1 (vehicle) voltage will be set to zero when DCM1 voltage is smaller than DCM2 voltage as equation (17). This

Table 2.

Testing parameters [18]

\begin{tabular}{ll}
\hline Parameters & Values \\
\hline Mass of car & $800 \mathrm{Kg}$ \\
\hline Mass of wheel & $5 \mathrm{Kg}$ \\
\hline Mass of motor drive & $5 \mathrm{Kg}$ \\
\hline Radius of wheel & $0.3 \mathrm{~m}$ \\
\hline Gearbox ratio & $1: 5$ \\
\hline Frontal area & $1.8 \mathrm{~m}^{2}$ \\
\hline Coefficient of rolling resistance & $0.01+3.6 *$ velocity \\
\hline Coefficient of aerodynamic drag & 0.55 \\
\hline Gravity & $9.8 \mathrm{~m} / \mathrm{s}^{2}$ \\
\hline
\end{tabular}

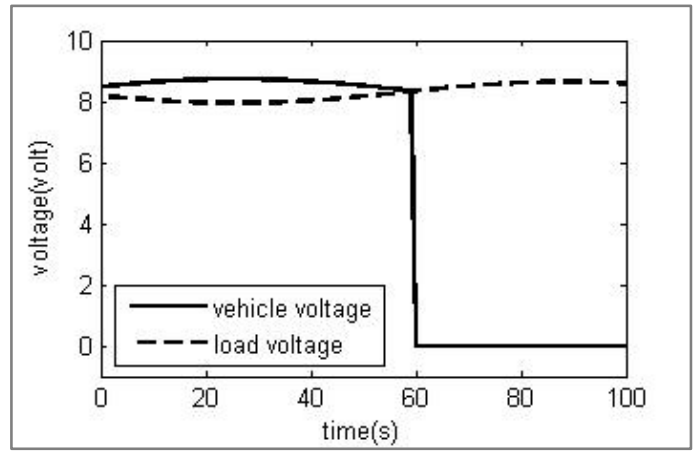

(a)

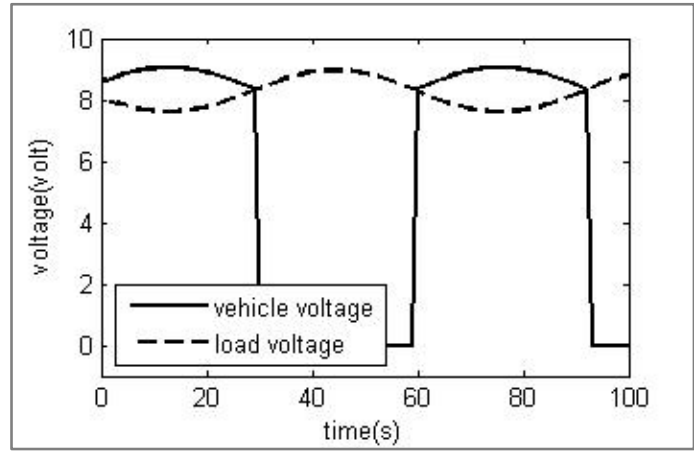

(b)

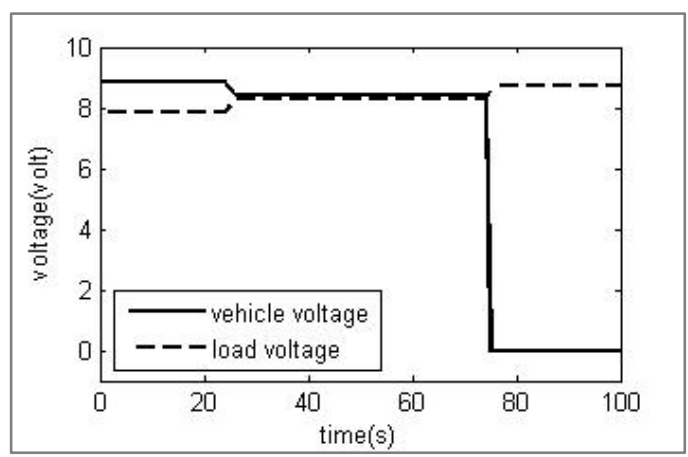

(c)

Figure 9. DCM voltages for each road profile: (a) one hill; (b) two hills; (c) trapezoidal 


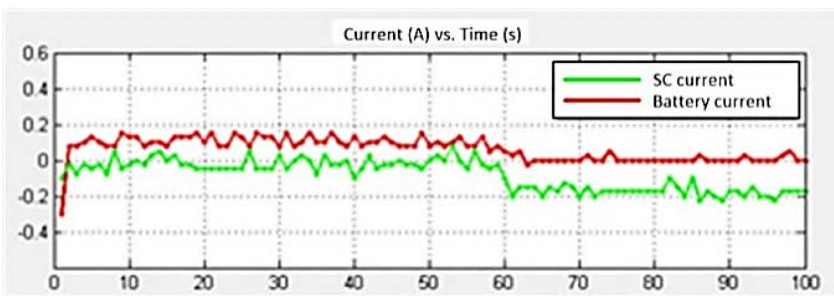

(a)

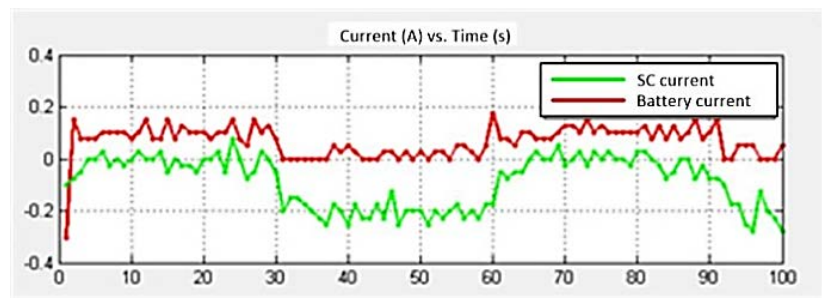

(b)

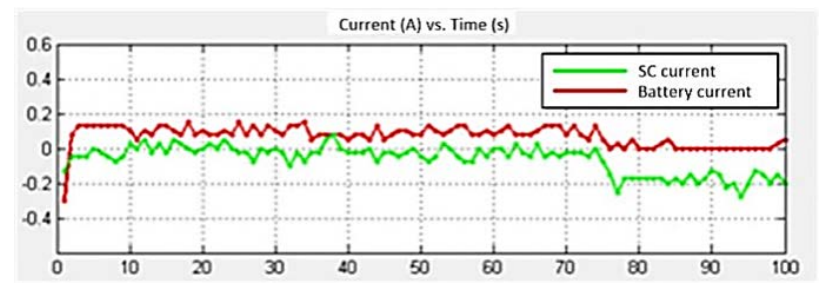

(c)

Figure 10. Supercapacitor charging currents for three road profile: (a) one hill; (b) two hills; (c) trapezoidal

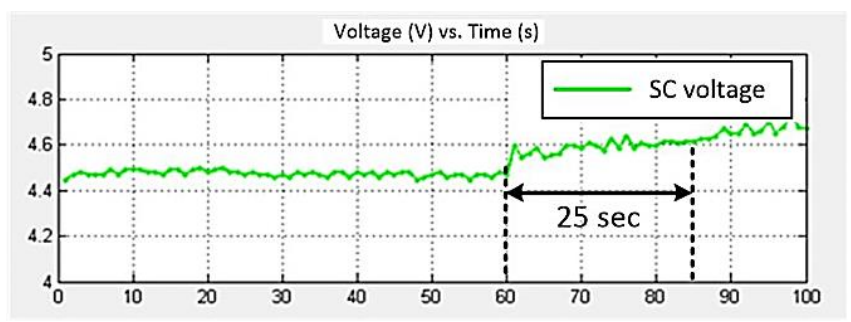

(a)

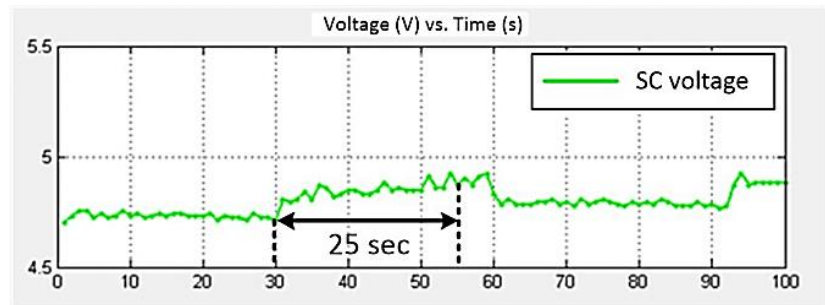

(b)

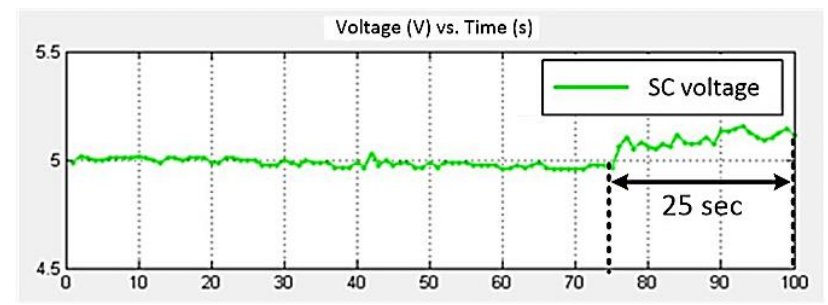

(c)

Figure 11. Supercapacitor voltages for each road profile: (a) one hill; (b) two hills; (c) trapezoidal

condition is used for supercapacitor charging. The discharging condition is conducted when the vehicle is at uphill or flat road profile under condition supercapacitor voltage is defined ready. Figure 10 and Figure 11 show the supercapacitor charging currents and its voltages. Different 
slope angle for each road profile resulted in different charging rate, which is shown by the different of supercapacitor charging current. Average values of charging current for three road profiles respectively are $-0.19 \mathrm{~A},-0.21 \mathrm{~A}$, and $-0.20 \mathrm{~A}$. The increases of supercapacitor voltage are also different for each road profile. Values of the increase of supercapacitor voltage (during 25 seconds for similarity) respectively are $0.15 \mathrm{~V}$, $0.17 \mathrm{~V}$, and $0.16 \mathrm{~V}$. Based on these values above, it showed that the biggest charging current is found in the two hills road profile that has a maximum slope angle $-16.66^{\circ}$. On the other hand, the smallest charging current is found on the one hill road profile with a maximum slope angle $-8.52^{\circ}$.

Based on hardware experimental results, the steeper the hill slope, the higher the supercapacitor charging current, which produces a quicker charging rate. This fact is shown by the increase of supercapacitor voltage. As a consideration, current and voltage values obtained are also not much different (around of $0.01 \mathrm{~A}$ ). It is due to slope angle difference between third road profiles less than $9^{\circ}$. In order to obtain the significant current difference, several ways may be taken, i.e. designing road profiles with higher slope angle or by making a vehicle's mass become heavier. However, the higher slope angle value or mass of the vehicle, DCM voltages which are obtained will also be higher.

\section{Conclusion}

A small-scale hardware EVS has been built and a simple supercapacitor charging scheme has been designed and successfully implemented in the hardware. Hardware experimental result shows that the averages of charging current are different and proportional with the maximum slope angle of the road profiles. It also has the impact on the change of supercapacitor voltage. This scheme is simple due to the EVS utility and it is useful for education purpose.

\section{ACKNOWLEDGEMENT}

The authors would like to thank the laboratory for control and computer systems (LSKK) Institut Teknologi Bandung for supporting laboratory facilities in this research.

\section{REFERENCES}

[1] A. Khaligh and Z. Li, "Battery, ultracapacitor, fuel cell, and hybrid energy storage systems for electric, hybrid electric, fuel cell, and plugin hybrid electric vehicles:
State of the art," IEEE Trans. Veh. Technol., vol. 59, no. 6, pp. 2806-2814, July 2010.

[2] M. Choi et al., "Energy management optimization in a battery/supercapacitor hybrid energy storage system," IEEE Transactions on Smart Grid, Vol. 3, No. 1, pp. 463-472, March 2012.

[3] S. Pay and Y. Baghzouz., "Effectiveness of battery-super capacitor combination in electric vehicles,” IEEE Bologna PowerTech Conference, pp. 728-733, June 2003.

[4] Y. C. Zhang et al., "Study of Supercapacitor in the Application of Power Electronics," WSEAS Transaction on Circuits and Systems, vol. 8, Issue 6, pp. 508-517, ISSN: 1109-2734, June 2009.

[5] A. B. Cultura and Z. M. Salameh, "Modeling, evaluation and simulation of a supercapacitor module for energy storage application," International Conference on Computer Information Systems and Industrial Applications (CISIA), pp. 876-882, 2015.

[6] M. S. W. Chan et al., "Effective charging method for ultracapacitors," Journal of Asian Electric Vehicles, Vol. 3 No. 2, pp. 771-776, December 2005.

[7] S. Ban et al., "Charging and discharging electrochemical supercapacitors in the presence of both parallel leakage process and electrochemical decomposition of solvent," Electrochimica Acta, vol. 90, pp. 542-549, 2013.

[8] Y. Diab et al., "Comparison of the different circuits used for balancing the voltage of supercapacitors: studying performance and lifetime of supercapacitors," ESSCAP, Lausanne, Switzerland, Nov. 2006.

[9] Y. Qu et al., "Overview of supercapacitor cell voltage balancing methods for an electric vehicle," ECCE Asia Downunder (ECCE Asia) IEEE, 2013.

[10] A. Botelho and W. Price, "Protodrive: Rapid prototyping and simulation for $\mathrm{EV}$ powertrains," ESE 350: Embedded Systems/Microcontroller Laboratory, University of Pennsylvania, 2012.

[11] S. Diaz et al., "Protodrive: An experimental platform for electric vehicle energy scheduling and control,” Dept. Electrical and System Engineering, University of Pennsylvania, 2012.

[12] S. Diaz, "Protodrive: Simulation of electric vehicle powertrains," NSF summer undergraduate fellowship in sensor technologies, Binghamton University, 2012. 
[13] W. Price, "Protodrive,” Project Technical Note, 2012.

[14] A. Mulay et al., "Protodrive: Rapid prototyping platform for electric vehicle powertrain,” Project Technical Note, 2013.

[15] A. R. Al Tahtawi and A. S. Rohman, "Simple supercapacitor charging scheme in electrical car simulator using direct current machines," Proceeding of The 5th IEEE International Conference on Electrical
Engineering and Informatics (ICEEI) Bali, pp. 562-567, 2015.

[16] M. Ehsani et al., "Modern electric, hybrid electric, and fuel cell vehicles Fundamentals, theory, and design," first ed., CRC Press LLC, 2005.

[17] Nesscap 100F/2.7F Ultracapacitor Datasheet, Nesscap Co., Ltd. 2003.

[18]E. Schaltz, "Electric vehicle design and modeling," Aalborg University, Denmark, INTECH Open Acces Publisher, 2011. 